\title{
Memory for the form and force of declaratives and interrogatives
}

\author{
SUSAN KEMPER \\ University of Kansas, Lawrence, Kansas 66045
}

\begin{abstract}
Memory for the illocutionary force and surface form of direct and indirect speech acts was studied in two recall tasks. Both examined the effects of the context of original presentation on subjects' ability to recall declarative and interrogative sentences. Subjects more accurately recalled the verbatim form of indirect requests and offers than that of direct assertions and queries. When prompted by contexts that preserved or changed in illocutionary force of a declarative or interrogative, subjects were equally likely to recall sentences originally used as indirect requests and offers. However, they more frequently recalled sentences originally used as direct assertions or queries when prompted by force-preserving contexts than when prompted by force-changing contexts.
\end{abstract}

The propositional content of a sentence may be distinguished from its surface form and its illocutionary force (Austin, 1962; Searle, 1969). Searle (1975a, $1975 \mathrm{~b}$ ) argues that the content and form of indirect speech acts are determined by rules governing the felicitous performance of illocutionary acts. For example, a speaker can indirectly request that someone pass her the salt by directly asking if the hearer is able to do so ("Could you pass the salt?") or if the hearer could, in the future, do so ("Will you pass the salt?"), or by stating that there are good reasons for doing so ("I would like some salt.") or that she would like the hearer to do so ("I would like you to pass the salt."). Each of these ways of indirectly requesting the salt exploits a different condition for the felicitous performance of a request; they differ in their syntactic form (i.e., declaratives vs. interrogatives) and propositional content (i.e., the hearer's salt-passing abilities vs. the speaker's wishes). Ervin-Tripp (1976) and Lakoff (1977) have suggested that cultural conventions determine the form of speech acts. The acceptability of "Pass the salt," "I would like some salt," and "Could you pass the salt?" depends on the situational context, the familiarity and status of speaker and hearer, and rules for politely requesting. Lakoff suggests that, in general, questions are more polite than declaratives and both are more polite than imperatives when used as requests and offers. The work of Clark (1979; Clark \& Lucy, 1975) demonstrates that readers and listeners evaluate not only the content and form of a sentence, but also the situational context in order to determine illocutionary force.

The processes involved in memory for the content,

This research was supported by University of Kansas General Research Allocation 3036-20-0038. The author thanks Guy Carden and an anonymous reviewer for their comments. Requests for reprints should be addressed to the author at the University of Kansas, Department of Psychology, 426 Fraser Hall, Lawrence, Kansas 66045. form, and force of sentences have been frequently compared. For example, in laboratory studies, the verbatim form of a sentence is more rapidly forgotten than its content (e.g., Jarvella, 1971; Sachs, 1967), yet the illocutionary force may be accurately remembered (Ackerman, 1978; Jarvella, 1974; Schweller, Brewer, \& Dahl, 1976). More recently, a series of studies have examined memory for the surface form of naturally occurring statements (Bates, Kintsch, \& Masling, 1978; Keenan, MacWhinney, \& Mayhew, 1977; Kintsch \& Bates, 1977). These studies suggest that people remember the surface form of sentences that are high in "interactional content," such as humorous remarks or jokes, and of sentences that convey explicit referential information. Bates et al. suggest that "the probability that a given surface form will be retained will, at least in part, be a function of the pragmatic role that surface form plays in a given context" $(1978$, p. 196).

The form of speech acts may convey pragmatically important information about the familiarity and status of the participants in a conversation. It may signal whether or not the speaker is flouting politeness conventions or Gricean conversational maxims (Grice, 1975). Readers may accurately remember the form of indirect speech acts as a result. Experiment 1 demonstrates that contextual information can bias the interpretation of declaratives and interrogatives. Experiment 2 compares readers' memory for the verbatim form of declaratives and interrogatives when used as direct assertions and queries and when used indirectly as requests and offers. Experiment 3 investigates readers' memory for actual and potential illocutionary force.

\section{EXPERIMENT 1}

This experiment was designed to evaluate the effectiveness of contextual information in determining the illocutionary force of declaratives and interrogatives. 
Readers were asked to provide speech-act interpretations of a set of sentences. The sentences were presented in isolation, in contexts that were neutral with respect to the illocutionary force of the remarks, or in contexts that were designed to bias the preferred speech-act interpretation of the remarks.

\section{Method}

Subjects. Sixty native speakers of English were recruited from introductory psychology classes. All received course credit for their participation.

Materials. Twelve interrogative and 12 declarative sentences were selected from a corpus of utterances spontaneously used in conversations as indirect speech acts. None of these sentences contained explicit performative verbs. Two paragraph contexts were prepared for each sentence. The construction of these paragraphs was based on the original indirect use of the sentence and guided by the conditions governing speech acts as outlined by Ervin-Tripp (1976) and Searle (1975b). One context was designed to be neutral with respect to the illocutionary force of the sentence; the other was designed to bias the reader toward an indirect interpretation. Examples are provided in Table 1.

In the neutral contexts, the declaratives were intended to be interpreted as informative assertions; the speaker was simply providing some information. In the biasing contexts, the declaratives were intended to be interpreted as requests; the speaker was attempting to obtain a resource from the hearer. In the neutral contexts, the interrogatives were intended to be interpreted as queries; the speaker was attempting to obtain some information from the hearer. In the biasing contexts, Interrogatives 1-6 were intended to be interpreted as requests and Interrogatives 7-12 were intended to be interpreted as offers; the speaker was attempting to provide a resource. ${ }^{1}$

A preliminary study was done to ensure that the sentences were equally natural and appropriate conclusions in the neutral and biasing contexts. Fourteen judges read each pair of paragraphs and selected the one member of each pair in which they felt the final sentence was "most naturally and appropriately used." Neutral and biasing paragraphs were preferred equally often for declarative targets $\left[x^{2}(1)=.67, p>.10\right]$ and for interrogative targets $\left[x^{2}(1)=1.32, p>.10\right]$.

Table 1

Examples of Neutral and Biasing Paragraphs

\section{Declarative Target Sentence}

Neutral: Will and Margaret were strolling through the rose garden at the country club. Margaret thought that the groundskeeper was not doing his job. She said "The leaves really should be raked."

Biasing: On Saturday afternoon, Will was just sitting around watching the football game. Margaret thought that there were several other things he should do. She said "The leaves really should be raked."

\section{Interrogative Target Sentence}

Neutral: We had a fire drill at school yesterday. Everybody dashed out of the building in record time. After the building was empty, a lady who lives nearby walked over to us and said "Why are you just standing around?"

Biasing: Our track coach got really mad at the whole squad yesterday. We had had drills all afternoon and everyone was beat. Coach told us to run 3 laps before we quit. When nobody moved, he said "Why are you just standing around?"
Table 2

Mean Proportion of Biased Indirect Interpretations of Declaratives and Interrogatives

\begin{tabular}{lccc}
\hline & \multicolumn{3}{c}{ Context } \\
\cline { 2 - 4 } & None & Neutral & Biased \\
\hline Declaratives & .24 & .14 & .73 \\
Interrogatives & .12 & .02 & .74 \\
\hline
\end{tabular}

Experimental task and design. Three groups of subjects were formed; subjects in the first group received a randomly ordered list of 24 declaratives and interrogatives. They were instructed to read each sentence and to "tell us in your own words what a speaker might do when uttering each of these sentences." These subjects were told that speakers might "order someone else to do something, ask for information, inform someone of a fact, express a belief or opinion, offer assistance, or commit himself or herself to some course of action." Subjects in the other two groups received a booklet containing 24 paragraphs that ended with either a declarative or an interrogative. Subjects in Group 2 received the neutral paragraphs, and subjects in Group 3 received the 24 biasing paragraphs. These subjects were instructed to read each paragraph and to write down another sentence or phrase to describe "what the speaker was trying to do ... whether the speaker was providing information, ordering someone else to do something, making an offer."

\section{Results and Discussion}

The taxonomies of speech acts of Austin (1962), McCawley (1977), and Searle (1977) were adapted in order to classify the subjects' responses as assertions, queries, requests, offers, and other types of speech acts (e.g., excuses, accusations, promises, warnings, etc.).

Two naive judges independently classified the responses provided by each subject. Interjudge reliability was computed as: (number of agreements)/(number of agreements and disagreements). For declaratives, the interjudge reliability was .87 ; for interrogatives, it was .88. All disagreements were settled by discussion between the judges. Of the responses, $90 \%$ of those to declaratives were classified; $87 \%$ of those to interrogatives were classified. The responses that were not classified as speech acts included restatements or elaborations of contextual information or ascriptions of beliefs and desires to the speaker.

The proportion of "biased" responses was determined. Biased responses were (1) request interpretations of declaratives and of Interrogatives 1-6 and (2) offer interpretations of Interrogatives 7-12. Table 2 presents the mean proportion of biased responses for the declaratives and interrogatives in isolation and after neutral and biasing contexts.

Analysis of variance on the arcsin transformations of the proportion of biased responses was performed with syntactic form (declaratives vs. interrogatives) as a within-subjects factor. Context (none vs. neutral vs. biased) was a between-subjects factor. ${ }^{2}$

The main effects of syntactic form $[F(1,57)=12.78$, $p<.001]$ and context $[F(2,57)=434.75, p<.001]$ were significant. Their interaction was also significant 
$[F(2,57)=3.87, \mathrm{p}<.05]$. Biased, indirect, performative interpretations were more frequently provided of both declaratives and interrogatives in biasing paragraphs than of sentences occurring in isolation $[t(38)=14.00$, $\mathrm{p}<.01]$. Fewer biased, indirect interpretations were made of the sentences in neutral paragraphs than of isolated sentences $[t(38)=2.50, p<.05]$. Overall, more indirect interpretations were given for declaratives than for interrogatives. However, biased interpretations were equally common for declaratives and interrogatives in the biasing paragraphs $[\mathrm{t}(38)=.20, \mathrm{p}>.05]$, whereas biased interpretations of declaratives were more likely than biased interpretations of interrogatives after neutral paragraphs $[\mathrm{t}(38)=2.40, \mathrm{p}<.05]$ or when the sentences occurred in isolation $[\mathrm{t}(38)=2.40, \mathrm{p}<.05]$.

These results demonstrate that the information in the biasing paragraphs was sufficient to influence readers' interpretation of declaratives and interrogatives. Declaratives are more readily interpreted indirectly in isolation or in neutral paragraphs than are interrogatives, perhaps due to conventionalized uses of declaratives as requests. Experiments 2 and 3 used these paragraphs to examine readers' memory for the verbatim form and illocutionary force of indirect requests and offers.

\section{EXPERIMENT 2}

If the form of indirect requests and offers is particularly important for conveying information relevant to politeness, the form of a sentence used as an indirect request or offer may be more accurately remembered than the form of a sentence used directly as an assertion or query. In this experiment, subjects studied a set of remarks that occurred in isolation, were used directly, or were used indirectly in paragraph contexts. The subjects were later asked to recall these remarks. Verbatim recall of indirect requests and offers was predicted to be superior to the recall of direct assertions and queries to the extent that the form of indirect speech acts conveys important pragmatic information.

\section{Method}

Subjects. Thirty native speakers of English were recruited from introductory psychology classes. All received course credit for their participation.

Materials. The sets of paragraphs and declarative and interrogative remarks prepared for Experiment 1 were again used. Slight modifications were made to ensure that the paragraphs referred to each speaker by name.

Experimental task and design. Three groups of subjects were formed; the subjects in the first group received a randomly ordered list of 24 declaratives and interrogatives. Each remark was prefaced with the name of a fictitious character. The subjects were instructed to read this list of remarks and were told that they would be asked to recall the remarks. Subjects in Groups 2 and 3 were given a booklet containing 24 paragraphs (either 24 neutral paragraphs or 24 biasing paragraphs) and were instructed to read these, paying attention to the final remarks of the characters. They were also informed that they would be asked to recall these remarks. Following a 40-min interval, during which the subjects performed an unrelated task, all groups of subjects were tested on their recall of the target interrogatives and declaratives. Each subject was given a response sheet listing the names of the 24 characters and was asked to "recall the character's original remark."

\section{Results and Discussion}

The proportion of verbatim reproductions of the original declaratives and interrogatives was determined. While only verbatim reproductions were scored, it was not required that the sentences be correctly paired with the name of the original character. Table 3 presents the mean proportion of verbatim responses.

An analysis of variance on the arcsin transformations of these proportions was performed. Context (none vs. neutral vs. biased) was a between-subjects factor, and sentence type (declarative vs. interrogative) was a withinsubjects factor. The main effects of context $[F(2,27)=$ $41.29, \mathrm{p}<.001]$ and of sentence type $[\mathrm{F}(1,27)=8.56$, $\mathrm{p}<.01]$ were significant. However, the interaction was not $[F(2,27)=.07, p>.05]$. Verbatim recall of sentences used in biasing contexts was better than that of sentences used in neutral contexts $[\mathrm{t}(18)=5.25, \mathrm{p}<$ $.05]$ while recall of sentences after neutral contexts was more accurate than recall of isolated sentences $[\mathrm{t}(18)=$ $3.50, \mathrm{p}<.05]$.

Experiment 2 demonstrates that declaratives and interrogatives used indirectly as requests or offers are recalled verbatim more frequently than are those used directly as informative assertions or queries. Ervin-Tripp (1976) and Lakoff (1977) have argued that politeness conventions determine the form of requests and offers and thus give rise to indirect uses of declaratives and interrogatives. The form of an indirect request or offer may provide information about the status and familiarity of conversational participants. As a result, readers remember the form of indirect requests and offers more accurately than the form of direct assertions and queries. However, syntactic form also contributes to the memorability of sentences, since interrogatives were remembered more accurately than declaratives. The present research cannot distinguish between two interpretations of the main findings of Experiment 2. It may be that (1) indirect speech is more memorable than direct speech or (2) requests and offers are more accurately remembered than assertions and queries. Further research, using different types of sentential materials, is necessary in order to resolve this issue.

Table 3

Mean Proportion of Verbatim Reproductions of Declaratives and Interrogatives

\begin{tabular}{lccc} 
& \multicolumn{3}{c}{ Context } \\
\cline { 2 - 4 } & None & Neutral & Biased \\
\hline Declaratives & .38 & .57 & .73 \\
Interrogatives & .43 & .58 & .80 \\
\hline
\end{tabular}




\section{EXPERIMENT 3}

As Clark (1979) and Searle (1977) have argued, logically both the direct and indirect illocutionary force of an indirect speech act must be considered. The direct illocutionary force as well as the Gricean conversational maxims, for example, provide a rationale for the indirect illocutionary force. This experiment was designed to explore whether readers of indirect speech acts are sensitive to both the direct and indirect illocutionary forces. Readers were tested on their ability to recall declaratives and interrogatives when the original context was presented as a prompt and when recall was prompted by a new context that changed the illocutionary force of the appropriate response. When a new context was presented, one group was asked to recall remarks that had originally been used directly but could now appropriately be used indirectly. Another group was asked to recall remarks originally used indirectly when prompted by new contexts appropriate to their direct use. It was predicted that the latter group would be more successful than the former in recalling declaratives and interrogatives in new contexts if both the direct and indirect illocutionary forces had been salient during the initial presentation.

\section{Method}

Subjects. An additional 40 native speakers of English were recruited. All received course credit for their participation.

Materials. The sets of neutral and biasing contexts prepared for Experiment 2 were used.

Experimental task and design. Four groups of subjects were created. Subjects in Groups 1 and 2 initially received a booklet containing 24 paragraphs; each concluded with a declarative or interrogative used directly to inform or query. Subjects in Groups 3 and 4 received the 24 paragraphs concluding with indirect requests or offers. All subjects were instructed to read these paragraphs, paying attention to the final remarks. Subjects were told that they would be asked to recall these remarks. Following a 20-min interval, during which they performed an unrelated task, the subjects were given a new booklet containing 24 paragraphs with the final remark deleted. Subjects in Groups 1 and 3 received the same 24 paragraphs they had originally studied as recall prompts. They were instructed to recall the original concluding remarks. Subjects in Groups 2 and 4 received a set of 24 new paragraphs. For example, subjects in Group 2 initially studied neutral contexts, but during recall they were prompted with the biasing contexts. Subjects in Groups 2 and 4 were instructed to provide a concluding remark from those they had originally studied that "would be an appropriate thing to say in each of these new situations." These subjects were advised that only one of the original remarks would be appropriate in each of the new situations.

\section{Results and Discussion}

Only responses that were verbatim reproductions of the original remarks were scored; further, it was required that each response be supplied as the concluding remark for the appropriate neutral or biasing paragraph. Table 4 presents the proportion of appropriate verbatim responses produced by the four groups of subjects. An analysis of variance was performed on the arcsin transformations of
Table 4

Mean Proportion of Verbatim Responses When Prompted

With Contexts That Preserve the Ilocutionary Force or With Contexts That Change the Illocutionary Force

\begin{tabular}{ccc} 
Recall & \multicolumn{2}{c}{ Acquisition Context } \\
Context & Neutral & Biased \\
\hline Force-Preserving & .56 & .72 \\
Force-Changing & .38 & .69 \\
\hline
\end{tabular}

these proportions. The original context (neutral vs. biased) and the recall prompt (same vs. different) were between-subjects factors. Syntactic form (declaratives vs. interrogatives) was a within-subjects factor.

The main effect for original context was significant $[F(1,36)=54.31, p<.001]$, verbatim memory for remarks originally used indirectly was superior to verbatim memory for remarks originally used directly. The main effect for recall prompt was also significant $[F(1,36)=11.82, \mathrm{p}<.01]$; when the recall prompt matched the original context, verbatim memory was better than when a new context was provided as a prompt. However, the interaction between these two factors was also significant $[\mathrm{F}(1,36)=6.44, \mathrm{p}<.05]$. Subjects who originally read indirect uses of declaratives and interrogatives were able to recall these remarks equally well in contexts that preserved their illocutionary force and in contexts that changed their illocutionary force $[t(18)=.75, p>.05]$. In contrast, subjects who originally read direct uses of declaratives and interrogatives were better able to recall these remarks when prompted by the original context than when prompted by the new contexts $[\mathrm{t}(18)=4.50, \mathrm{p}<.01]$. There was no effect of syntactic form $[F(1,36)=2.72, p>.05]$.

These results suggest that readers are sensitive to both the direct and the indirect illocutionary force of indirect requests and offers. As a result, they are equally likely to reproduce the verbatim remark in contexts appropriate to either the direct or the indirect use. Readers are less sensitive to potential indirect uses of informative assertions or queries and hence are less able to reproduce such remarks in new contexts appropriate to their use as requests or offers than in old contexts.

\section{CONCLUSIONS}

As Lakoff (1977) and others have suggested, rules of politeness may determine the particular form of a request or offer. Readers may be sensitive to the particular form of an indirect request or offer because it conveys prag. matic information about the interpersonal characteristics of the participants in a conversation. As a result, readers more accurately recall the verbatim form of an indirect request or offer than that of a direct assertion or query. Readers are also sensitive to both the direct and the indirect illocutionary forces of indirect requests or offers. The direct illocutionary force contributes to the determination of the actual performative use of a 
declarative or interrogative. As a result, readers are likely to recall directly used declaratives and interrogatives when prompted by new contexts appropriate to their indirect use.

\section{REFERENCES}

Ackerman, B. P. Children's understanding of speech acts in unconventional frames. Child Development, 1978, 49, 311-318.

Austin, J. L. How to do things with words. Oxford: Oxford University Press, 1962.

Bates, E., Kintsch, W., \& Masling, M. Recognition memory for aspects of dialogue. Journal of Experimental Psychology: Human Learning and Memory, 1978, 4, 187-197.

Clark, H. H. Responding to indirect speech acts. Cognitive Psychology, 1979, 11, 430-477.

ClaRK, H. H., \& Lucy, P. Understanding what is meant from what is said: A study in conversationally conveyed requests. Journal of Verbal Learning and Verbal Behavior, 1975, 14, 56-72.

Ervin-TRIPP, S. Is Sybil there? The structure of some American English directives. Language in Society, 1976, 5, 25-66.

Grice, H. P. Logic and conversation. In P. Cole \& J. Morgan (Eds.), Syntax and semantics (Vol. 3). New York: Academic Press, 1975.

JARVELLA, R. Syntactic processing of connected speech. Journal of Verbal Learning and Verbal Behavior, 1971, 10, 409-416.

J ARvella, R. Memory for the intentions of sentences. Memory \& Cognition, 1974, 1, 185-188.

Kennan, J. M., MacWhinney, B., \& Mayhew, D. Pragmatics in memory: A study of natural conversation. Journal of Verbal Learning and Verbal Behavior, 1977, 16, 549-560.

KintsCh, W., \& Bates, E. Recognition memory for statements from a classroom lecture. Journal of Experimental Psychology: Human Learning and Memory, 1977, 3, 150-168.

LakorF, R. What you can do with words: Politeness, pragmatics, and performatives. In A. Rogers, B. Wall, \& J. P. Murphy (Eds.), Proceedings of the Texas conference on performatives, presuppositions, and implicatures. Arlington, Va: Center for Applied Linguistics, 1977.

MCCAWLEy, J. D. Remarks on the lexicography of performative verbs. In A. Rogers, B. Wall, \& J. P. Murphy (Eds.), Pro- ceedings of the Texas conference on performatives, presuppositions, and implicatures. Arlington, Va: Center for Applied Linguistics, 1977.

SACHS, J. Recognition memory for syntactic and semantic aspects of connected discourse. Perception \& Psychophysics, 1967, 2, 437-444.

Schweller, K. G., Brewer, W. F., \& Dahl, D. A. Memory for illocutionary forces and perlocutionary effects of utterances. Journal of Verbal Learning and Verbal Behavior, 1976, 15, $325-337$.

Searle, J. R. Speech acts. Cambridge: Cambridge University Press, 1969.

Se ARLE, J. R. Indirect speech acts. In P. Cole \& J. L. Morgan (Eds.), Syntax and semantics 3: Speech acts. New York: Academic Press, 1975. (a)

Se arle, J. R. Speech acts and recent linguistics. In D. Aaronson \& R. W. Reber (Eds.), Developmental Psycholinguistics and Communication Disorders. New York: NYAS, 1975. (b)

Se A RLE, J. R. A classification of illocutionary acts. In A. Rogers, B. Wall, \& J. P. Murphy (Eds.), Proceedings of the Texas conference on performatives, presuppositions, and implicatures. Arlington, Va: Center for Applied Linguistics, 1977.

\section{NOTES}

1. Care was taken to ensure that the contexts did not differ systematically in either (1) the mean number of words or (2) the mean number of clauses. The mean number of words for each type of context were (1) declarative targets: neutral contexts, 23.5 ; biasing contexts, $23.6[\mathrm{t}(11)=.70, \mathrm{p}>.05]$ and (2) interrogative targets: neutral contexts, 25.2 ; biasing contexts, 25.2 $[t(11)=.76, p>.05]$. The mean number of clauses for each type of context were (1) declarative targets: neutral contexts, 3.7 ; biasing contexts, $3.8[t(11)=.99, p>.05]$ and (2) interrogative targets: neutral contexts, 4.1 ; biasing contexts, 4.1 $[\mathrm{t}(11)=1.73, \mathrm{p}>.05]$.

2. Preliminary analysis revealed no systematic differences between the two sets of interrogatives in Experiments 1,2, or 3 . Responses to interrogatives used as requests $(1-6)$ and offers (7-12) were pooled in the reported analyses.

(Received for publication February 7, 1980; accepted March 10, 1980.) 